"normals" in postmortem toxicology. Non-circulating blood after death is not the same thing as circulating blood before death, and evidence that the concepts of normal or therapeutic drug concentrations can be applied to blood from dead bodies is severely lacking.

Even in living bodies, interpretation of a single blood concentration measurement is impossible without considering route of administration, number of doses taken, and the amount of drug actually in the body. Such information is almost never available to investigators, making it impossible to determine the cause of death solely by comparing a single postmortem drug concentration measurement with a range of published values, originally derived from measurements made in living people. With chronic use, tolerance occurs, and tolerance cannot be measured or estimated after death. Healthy patients enrolled in methadone maintenance programmes, for example, may have blood methadone concentrations in excess of other, non-tolerant methadone users examined on the autopsy table. ${ }^{1}$ Similarly, we have long known that blood sampled from the heart of a dead person who had been on long term digoxin treatment may contain a seemingly toxic concentration of digoxin when, in fact, the actual blood concentration immediately before death was the appropriate non-toxic therapeutic concentration. ${ }^{2}$

Even if it could be shown that blood concentrations after death were the same as concentrations at the time of death, which blood sample should be used? Drug concentrations are likely to have changed after death. ${ }^{3}$ For many drugs, including those found in David Kelly, concentrations may increase by as much as 10 -fold. ${ }^{4}$ Furthermore, drug concentrations in blood samples from cadavers are site dependent, higher in some locations and lower in others. ${ }^{5}$ Should the site yielding the lowest or highest result be used? Or should an average value for three sites be used? Nobody knows because the process has never been studied systematically.

If the blood concentration at the time of death cannot be known with certainty, then how is it possible to extrapolate the time and amount of drug ingested before death? The simple answer is that such extrapolations are prone to considerable error and generally should be viewed as unreliable and not evidence based. ${ }^{6}$ Despite these limitations, such calculations are frequently and wrongly produced during court proceedings, even though the problems we outline have been widely known for many years.

Postmortem measurements of drug concentration in blood have scant meaning except in the context of medical history, the sequence and circumstances surrounding death, and necropsy findings. The paucity of evidence based science, coupled with the pretence that such science exists in regard to postmortem toxicology, leads to the abuse of process, almost certainly to the miscarriage of justice, and possibly even to false perceptions of conspiracy and cover up.

We have written this editorial partly because of the Kelly matter, where the central issue concerned the interpretation of the toxicology results. Death investigation and forensic pathology are also not immune to misinterpretation. Poor or inadequate death investigation and incomplete or misinterpreted forensic pathology studies may also result in wrong conclusions. All aspects of the medicolegal death investigation triadinvestigation (history), pathology, and laboratory results-are essential and must be evaluated in context with one another. We have formed an ad hoc group to address this issue. A detailed analysis of the problem with suggestions for reform is in preparation.

\section{Olaf Drummer adjunct professor}

Victorian Institute of Forensic Medicine, 57-83 Kavanagh Street, Southbank, Victoria 3006, Australia (olaf@vifm.org)

A Robert W Forrest professor of forensic toxicology

University of Sheffield, Sheffield S3 7ES

(robertforrest@mac.com)

\section{Bruce Goldberger associate professor}

Department of Pathology, Immunology and Laboratory Medicine, University of Florida College of Medicine, PO Box 100275

Gainesville, FL 32610-0275, USA

(bruce-goldberger@ufl.edu)

Steven B Karch assistant medical examiner

PO Box 5139, Berkeley, California 94705-0139, USA

(skarch@sonic.net)

On behalf of the International Toxicology Advisory Group (ITAG) (see bmj.com for list of members).

Competing interests: appear on bmj.com

Karch SB, Stephens BG. Toxicology and pathology of deaths related to methadone: retrospective review. West J Med 2000;172:11-4.

2 McKercher HG, Mikhael NZ, De Gouffe M, Lukaszewski T, Peel HW. Digoxin concentrations in postmortem human tissues. Res Commun Chem Pathol Pharmacol 1986;52:141-4.

3 Pounder DJ, Jones GR. Post-mortem drug redistribution-a toxicological nightmare. Forensic Sci Int 1990;45:253-63.

Drummer $\mathrm{OH}$, Gerostamoulos J. Postmortem drug analysis: analytical and toxicological aspects. Ther Drug Monit 2002;24:199-209.

5 Hearn WI Keran EE, Wei HA, Hine G. Site-dependent postmortem changes in blood cocaine concentrations. J Forensic Sci 1991;36:673-84.

Cook DS, Braithwaite RA, Hale KA. Estimating antemortem drug Cook DS, Braithwaite RA, Hale KA. Estimating antemortem drug
concentrations from postmortem blood samples: the influence of postmortem redistribution. J Clin Pathol 2000;53:282-5.

\title{
Compulsory registration of clinical trials
}

\section{Will be a requirement before submission to the BMJ from July 2005}

"T The case for registering all clinical trialsfirst advanced a decade ago ${ }^{1}$-is now unanswerable."' Editors of the BMJ and the Lancet made this statement in 1999. Five years of industry resistance, government impotence, and public confusion followed. Medical journals persisted with noble intentions and wise words but were themselves in part resistant, impotent, and confused about how to enforce registration. Some journals, including the $B M J$, tried an amnesty for unpublished trials, with little success. $^{3}$ The $B M J$ also considered asking for compulsory registration, but it seemed to us that trial registries were too diverse, disorganised, and easily disregarded to insist on registration before submission. Nor did we 
want fees for registering trials to be a barrier to researchers wanting to publish in the BMJ.

The world has changed. Undisclosed trials and duplicate and selective publication sting government agencies, clinicians, researchers, and journals ever more frequently and painfully. Crucially, this form of misconduct, which Iain Chalmers identified in 1990, distorts the scientific record. ${ }^{4}$ By suppressing negative findings and exaggerating positive ones, by downplaying harms and talking up benefits, healthcare decisions are based on incomplete data and ultimately harm the patients.

A $B M J$ theme issue last year spelt out the myriad entanglements between doctors and the drug industry, arguing that a new relationship based on transparency and trust was needed to protect patients. ${ }^{5}$ This year's speed of reform has put the drug industry on the back foot. Most notably, Eliot Spitzer, New York's attorney general, won a landmark legal case against GlaxoSmithKline forcing disclosure of undisclosed trial data on paroxetine in adolescents, data that support a long campaign to highlight its harmful effects. ${ }^{6}$

This week, many of the world's leading medical journals-those belonging to the International Committee of Medical Journal Editors (ICMJE)announced a tough stance on trial registration. Trials that begin enrolment of patients after 1 July 2005 must register in a public trials registry at or before the onset of enrolment to be considered for publication in those journals. Trials that began patient enrolment on or before 1 July 2005 must register before 13 September 2005 to be considered for publication. ${ }^{7}$ This is a policy we support, and we will use the same deadlines for consistency-albeit with a couple of important differences.

Firstly, we believe it is wrong to be too prescriptive about the choice of registry because registries for trials are in an early stage of development. The ICMJE statement proposes a set of essential criteria and says that it "does not advocate one particular registry," although only one registry meets its criteria: www.clinicaltrials. gov, a registry sponsored by the US National Library of Medicine. This exclusive endorsement by the ICMJE journals is perplexing because clinicaltrials.gov offers registration only to "federal agencies sponsoring the clinical research studies (both interventional and observational trials), private sponsors that have submitted an Investigational New Drug Application (IND) to the Food and Drug Administration (FDA), such as pharmaceutical companies, and organizations representing IND sponsors." These restrictive entry criteria will not be met by many trials worldwide. An inquiry from one of the $B M$ Fs editorial board members about registering non-drug, non-National Institutes of Health trials emanating from low or middle income countries was met with this response: "The sorts of trials you have described are not eligible for registration in clinicaltrials.gov at this time."

The $B M J$ s criteria for a suitable registry are listed in the box. As registries become more sophisticated we may have to revise these criteria. For example, because hundreds of registries exist there is already a role for a database-a metaregister-that aggregates trial information in individual registries. Individual registries should allow their contents to be aggregated. A way of recording or linking to the results of trials might

\section{The $B M J$ s criteria for a suitable registry}

Free to access, searchable, and identifies trials with a unique number

Registration is free or has minimal cost

Registered information is validated

Registered entry includes details to identify the trial and investigator and includes the status of the trial The research question, methodology, intervention, funding, and sponsorship must all be disclosed

become an essential criterion, as might information on competing interests and ethical approval.

Examples of registries that meet our proposed initial criteria are the International Standard Randomised Controlled Trial Number (ISRCTN) registry, managed by Current Controlled Trials-a commercial company that also owns BioMed Central and a metaregister (www.controlled-trials.com)-clinicaltrials.gov, and the UK National Register of Cancer Trials (http:// 212.219.75.236/ukcccr). The ISRCTN registry is not publicly owned-public ownership is one of the criteria in the ICMJE statement-but its content is freely available to the public. Registration of trials in the ISRCTN registry is free for trials that are "sponsored, funded, and carried out in developing and transitional countries, in line with HINARI (Health InterNetwork Access to Research Initiative)." The registration fee for all other trials is $£ 80$ ( $\$ 144 ; € 117)$. Our view is that although public ownership is valuable, free public access suffices as an essential criterion-whether ownership is public or private-and that an international registry is preferable to one focusing on the research needs of one nation. This is not to undermine the ICMJE journals, but we believe that these modified criteria are more equitable and inclusive.

Will this move by journal editors work? On their own, journals can change little quickly, but with the public and governments (particularly the United States) whipping up a storm around the drug industry-and the researchers who conspire with industry to suppress findings that may harm patients and profits-journals have just done the public a service. The real question is how will industry respond? Missing out on the chance of publishing favourable findings in prestigious journals by not complying with this policy is undesirable for industry but the battleground will shift to monitoring of trials and ensuring that results-good, bad, or indifferent-are reported.

Kamran Abbasi acting editor BMJ

Competing interests: None declared.

1 Simes RJ. Publication bias: the case for an international registry of clinical trials. J Clin Oncol 1986;4:1529-41.

2 Horton R, Smith R. Time to register randomised trials. BMJ 1999;319: $865-6$

3 Roberts I. An amnesty for unpublished trials. BMJ 1998;317:763-4.

4 Chalmers I. Underreporting research is scientific misconduct. JAMA 1990;263:1405-8.

5 Abbasi K, Smith R. No more free lunches. BMJ 2003;326:1155-6.

6 Dyer O. GlaxoSmithKline to set up comprehensive online clinical trials register. BMJ 2004;329:590-1.

7 De Angelis C, Drazen JM, Frizelle FA, Haug C, Hoey J, Horton R, et al. Clinical trial registration: a statement from the International Committee of Medical Journal Editors. Lancet 2004:364:911-2.

8 FAQ. ClinicalTrials.gov-submitting trial information to ClinicalTriFAQ. ClinicalTrials.gov-submitting trial information to ClinicalTri-
als.gov www.nlm.nih.gov/services/ctgetfaq.html (accessed 13 Sep 2004). 